\title{
The impacts of traditional and novel herbicide application methods on target plants, non-target plants and production in intensive grasslands
}

\author{
E F POWER, D L KELLY \& J C STOUT \\ Trinity Centre for Biodiversity Research, Botany Building, School of Natural Sciences, Trinity College Dublin, Dublin, Ireland
}

Received 28 November 2011

Revised version accepted 29 October 2012

Subject Editor: Claudio Ghersa, IFEVA UBA-CONICET, Argentina

\section{Summary}

Herbicides contribute significantly to agricultural intensification, but some negatively impact non-target organisms. Much research has focused on reducing herbicide use through technological improvements in application and herbicide selectivity, but impacts on non-target organisms are less well understood. Using experimental plots in silage systems, we investigated impacts of herbicides (both narrow spectrum targeting broad-leaved plants and selective and non-selective broad spectrum) applied using traditional techniques (blanket- and manual spot-spraying) and a novel application technique (automated spot-spraying) on non-target plant richness/diversity, target weed presence (Rumex species) and production (DM yield). All herbicides reduced non-target plant richness/diversity and sometimes target weeds (when applied using traditional methods). Automated spot-spraying had fewer negative effects on non-target organisms, but did not reduce target weeds. No differences in production levels among treatments were observed. The automated spot-spraying technique requires further research and development. Our results indicate that $20-30 \%$ weed cover does not significantly alter production and so, as herbicides are expensive, their effects on non-target organisms and the environment can be more significant than their benefits to production. We advocate more research into the relationships between weed infestation and production in grasslands, so that the propensity to overuse herbicides is reduced.

Keywords: fluroxypyr, triclopyr, aminopyralid, glyphosate, biodiversity, agroecology, precision agriculture, weed control, sustainable agriculture.

Power EF, Kelly DL \& Stout JC (2013). The impacts of traditional and novel herbicide application methods on target plants, non-target plants and production in intensive grasslands. Weed Research.

\section{Introduction}

Agricultural intensification has contributed to the impoverishment of European farmland biodiversity. In particular, many of the plant species associated with lowland farmed landscapes have shown marked contractions in geographic range and severe declines in abundance (Sutcliffe \& Kay, 2000). The decline of wild plant species has been driven by post-World War II agricultural intensification, in which the herbicidal control of weeds played a major part (Bastiaans et al., 2008). Many undesirable wild plant species associated with agriculture are known as weeds, as they capture a part of the available resources that may result in a reduction in crop yield. Chemical weed control is currently the standard management approach, with various broad-spectrum and selective herbicides available. Some chemicals can have a negative effect 
on farmland biodiversity by directly affecting organisms both in the field and in nearby habitats or indirectly by having knock-on effects at higher trophic levels in the agroecosystem (Marshall et al., 2003). Repeated use can cause shifts in weed communities and selection for herbicide-resistant biotypes (Andreasen \& Streibig, 2010). Furthermore, they may pollute aquatic environments including ground water, lakes, rivers, estuaries and coastal marine waters (Steen et al., 1999), and there are widespread concerns over possible impacts on food safety and public health (Shaw, 1999).

There has, in consequence, been much research focused on ways of reducing or eliminating herbicide usage (Bastiaans et al., 2008). These include technological advances in herbicide application (e.g. Brown et al., 2007), including machine vision technology (Gebhardt et al., 2006), plant identification technology (Tillett et al., 1998) and targeted area spraying (Blair et al., 2002). Such technologies aim to replace existing methods such as blanket-spraying (leading to an overuse of herbicide, impacts on non-target organisms and high economic costs for the farmer) or manual spotspraying of individual weeds (which is labour-intensive but potentially reduces environmental impacts). However, little research has been conducted on how traditional herbicide application techniques and new application technologies compare in their effects on biodiversity. In addition, it is unclear how application method affects impacts of different broad-spectrum and selective herbicides. It is of critical importance to find a balance between controlling problem weeds, maintaining production and minimising negative impacts of herbicides. Furthermore, although frequent defoliation combined with high fertiliser application rates is known to result in structurally homogeneous, species-poor swards (Vickery et al., 2001), the interaction effects of silage cutting and herbicides on biodiversity are less clear.

Previous research into effects of herbicides on plant diversity has primarily addressed arable systems, with limited reference to intensively managed grasslands. Our study focused on intensive lowland grasslands that cover millions of hectares in Europe (Plantureux et al., 2005) and constitute the majority of agricultural land in Ireland (Central Statistics Office, 2010). We addressed the interactive impacts of different herbicide types applied using traditional and novel application techniques and silage cutting on non-target plants, target plants and production. We tested a triclopyrfluroxypyr formulation, which is a narrow-spectrum broad-leaved weed herbicide, an aminopyralid-fluroxypyr formulation, which is selective broad-spectrum, and glyphosate, which is non-selective broad-spectrum herbicide. These were applied using blanket-spraying and manual spot-spraying and automated spotspraying, a technique known as precision pasture management (PPM) that uses plant ID technology to specifically target and spot-spray individual weeds (Mcloughlin, 2011).

\section{Materials and methods}

\section{Experimental details}

Experimental plots were established in intensively managed grasslands at three sites in the Republic of Ireland owned by Teagasc (the Irish Agriculture and Food Development Authority): Moorepark Research Centre (Fermoy, Co. Cork), Oakpark Crops Research Centre (Co. Carlow) and Kilmaley Research Farm (Co. Clare). All study sites had low plant species richness comparable with typical permanent pasture conditions in Ireland, which are dominated by Agrostis and Lolium species. Study sites had a pre-existing weed infestation with $20-30 \%$ cover of Rumex obtusifolius L. (Broad Dock) and Rumex crispus L. (Curled Dock) (Supporting information Fig. S1). This infestation level was considered enough to initiate weed control by land managers (pers comm.: O'Donovan, M). The two Rumex species were chosen as the target weeds for this study, and typical herbicides for this location were selected. All other plant species (forb and grass) were considered non-target species. This included some species often considered to be weeds but which were not common enough to warrant control measures.

Experiment 1 was established in all three sites in spring 2008 and ended in autumn 2009 (two growing seasons); Experiment 2 was established in Moorepark and Oakpark in spring 2009 and ended in autumn 2010 (two growing seasons). A replicated randomised block design with one control and five treatments in four replicate blocks was used, resulting in 24 plots per site per experiment (Supporting Information Fig. S1). Plots at two sites, Moorepark and Oakpark (Experiments 1 and 2), were $6 \mathrm{~m} \times 15 \mathrm{~m}$, whilst plots at Kilmaley were $6 \mathrm{~m} \times 5 \mathrm{~m}$ (due to space restrictions). Therefore, subplots of $6 \mathrm{~m} \times 5 \mathrm{~m}$ were established within the other sites to standardise plant surveys with the Kilmaley plots (Supporting Information Fig. S2). Buffer zones of $1 \mathrm{~m}$ were established between plots and $3 \mathrm{~m}$ between blocks. Experiment 1 focused on the effects of three commonly used herbicide formulations (triclopyr-fluroxypyr, aminopyralid-fluroxypyr and glyphosate) and their two main application methods (blanket versus manual) on botanical diversity. The triclopyr-fluroxypyr formulation (Doxstar EC, $100 \mathrm{~g}$ a.i. $\mathrm{L}^{-1}$ triclopyr, $100 \mathrm{~g}$ a.i. $\mathrm{L}^{-1}$ fluroxypyr, Dow AgroSciences) is designed to be selective for the 
control of Rumex species (docks) in established grassland. The aminopyralid-fluroxypyr formulation (Forefront WOE, $30 \mathrm{~g}$ a.i. $\mathrm{L}^{-1}$ aminopyralid, $100 \mathrm{~g}$ a.i. $\mathrm{L}^{-1}$ fluroxypyr, Dow AgroSciences) is designed to be a broad-spectrum broad-leaved herbicide formulation used to control over 60 broad-leaved plant species. Glyphosate (Roundup SC, $450 \mathrm{~g}$ a.i. $\mathrm{L}^{-1}$, Monsanto) is a broad-spectrum herbicide that is used to control annual and perennial grasses, as well as broad leaves. The control and five treatments for Experiment 1 were as follows:

1 No herbicide application - control (C)

2 Blanket-spraying of triclopyr-fluroxypyr (BD)

3 Blanket-spraying of aminopyralid-fluroxypyr (BF)

4 Manual spot-spraying with triclopyr-fluroxypyr (MD)

5 Manual spot-spraying with aminopyralid-fluroxypyr (MF)

6 Manual spot-spraying with glyphosate (MR)

Blanket-spraying involved spraying the entire plot with herbicide. In our study, there was no treatment involving blanket-spraying of glyphosate, due to the indiscriminate action of this herbicide on all plants. Manual spot-spraying is used to target herbicide spray at specific weed individuals. It was carried out by one individual using a spray pack.

Experiment 2 focused on the effects of a novel herbicide application technique on botanical diversity using the same three herbicides (glyphosate, triclopyrfluroxypyr and aminopyralid-fluroxypyr). The control and five treatments were as follows:

1 No herbicide application - control (C)

2 Blanket-spraying of triclopyr-fluroxypyr (BD)

3 Blanket-spraying of aminopyralid-fluroxypyr (BF)

4 Automated spot-spraying of triclopyr-fluroxypyr (PD)

5 Automated spot-spraying of glyphosate (PR)

6 Automated spot-spraying of aminopyralid-fluroxypyr (PF)

The automated spot-spraying technique is a tractormounted technology (known as precision pasture management or PPM) that identifies weeds (using plant ID technology) and sprays the individual weed leaving the rest of the area spray-free (Mcloughlin, 2011). Herbicide applications were applied once in each experiment, 21 days after the first silage cut in the first year. As per manufacturer guidelines, the application rate for the triclopyr-fluroxypyr mixture was $300 \mathrm{~g}$ a.i. $\mathrm{ha}^{-1}$ each in $300 \mathrm{~L} \mathrm{ha}^{-1}$, and the rate for glyphosate was $1.35 \mathrm{~kg}$ a.i. ha $\mathrm{ha}^{-1}$ in $200 \mathrm{~L} \mathrm{ha}^{-1}$. The application rates for the aminopyralid-fluroxypyr mixture were $60 \mathrm{~g}$ a. i. $\mathrm{ha}^{-1}$ and $200 \mathrm{~g}$ a.i. $\mathrm{ha}^{-1}$, respectively, also in
$300 \mathrm{~L} \mathrm{ha}^{-1}$. Flat-fan nozzles (Hardi ISO, F/LD, 3-110) at a pressure of $300 \mathrm{KPa}$ were used. The volume of active ingredient applied per unit area was recorded for the automated and blanket application treatments only. All plots received fertilisation levels of $c$. $220 \mathrm{~kg} \mathrm{~N} \mathrm{ha}^{-1}$ year $^{-1}$; three cuts of silage were taken annually in May, July and September.

\section{Plant surveys}

Plants were surveyed seven times in each plot in each experiment at each site. In the first growing season, surveys were carried out once prior to: (1) the 1st silage cut,(2) the treatment application, (3) the 2nd silage cut and (4) the 3rd silage cut. In the second growing season, surveys were performed once prior to: (5) the 1st silage cut, (6) the 2nd silage cut and (7) the 3rd silage cut. Due to unforeseen circumstances, surveys 2 and 7 could not be conducted in Experiment 1 in Kilmaley, and survey 7 could not be conducted in Experiment 2 in Moorepark and Oakpark. Plants were surveyed using the random placement of three (Experiment 1) or two (Experiment 2) $0.5 \mathrm{~m} \times 0.5 \mathrm{~m}$ quadrats in each plot. In each quadrat, all vascular plant species, as well as the percentage cover of each, were noted. Nomenclature follows Stace (2010). A total of 1804 quadrats measurements were thus taken in the two experiments at the three sites, over the seven survey periods. Non-target total plant (excluding Rumex species), grass and forb species richness and plant diversity [Simpson's Index of Diversity (1-D) (Simpson, 1949)] and percentage cover of the target weed species (Rumex species) were calculated for each quadrat.

\section{Production}

Dry matter production $\left(\mathrm{kg} \mathrm{DM} \mathrm{ha}{ }^{-1}\right)$ above $4 \mathrm{~cm}$ was estimated prior to each silage cut by cutting a 6-m strip of vegetation across the centre of each plot $(6 \mathrm{~m} \times 15 \mathrm{~m}$ plots in Moorepark and Oakpark and $6 \mathrm{~m} \times 5 \mathrm{~m}$ plots in Kilmaley) using a motor Agria machine (Etesia UK Ltd., Warwick, UK). A subsample $(100 \mathrm{~g})$ of vegetation was taken at random from the harvested material and was dried at $80^{\circ} \mathrm{C}$ for $16 \mathrm{~h}$ to determine the quantity of dry matter ( $\mathrm{kg} \mathrm{DM}$ ). Herbage dry matter yield $\left(\mathrm{kg} \mathrm{DM} \mathrm{ha}^{-1}\right)$ was then calculated for each plot.

\section{Statistical analysis}

Total plant, grass and forb species richness and plant diversity were analysed in relation to (1) herbicide treatment and silage cutting, (2) carry-over effects 
(growing season 1 to 2 ) of herbicide treatment and silage cutting and (3) pre- versus post-herbicide treatment and silage cutting using linear mixed effects models. Also (4), the presence/absence of Rumex species in plots pre- versus post-herbicide treatment was analysed using binomial generalised linear mixed models (GLMM). For each analysis (except in silage-cutting models in analyses 2 and 3 that were based on control plots only), all quadrats in all plots, replicates, sites and survey periods were analysed together. We accounted for spatial autocorrelation by including random terms: plot (1-120), replicate [1-4 (Experiment 1), 5-8 (Experiment 2)], site (Moorepark, Oakpark, Kilmaley), survey period (1-7), year (2008, 2009, 2010). Fixed effects for each analysis included the following: (1) herbicide treatment (1-9) and silage cut (none, one cut, two cuts), (2) herbicide treatment or silage cut and growing season (season 1 or 2 in relation to Experiments 1 or 2), (3) pre- and postherbicide treatment or silage cut and (4) pre- and post-herbicide treatment. Relevant two-way interactions between fixed effects were also included. Production (5) at each site was analysed using general linear models (GLM). Fixed effects included herbicide treatment [1-6 (Experiment 1), 1-3, 7-9 (Experiment 2)]. Mixed models were simplified by removing first nonsignificant interactions $(P>0.05)$ and then any nonsignificant main effects (that were not constituent within a significant interaction). For model structure, validation and adequacy assessment, we followed Zuur et al. (2009). Mixed modelling was carried out using the nlme (Pinheiro et al., 2009) and Ime4 (Bates \& Sarkar, 2006) package in R ( R Development Core Team, 2007). Production analysis was carried out using SAS (2002).

\section{Results}

The amount of active ingredient applied of each herbicide differed among treatments. The automated application method used three times less herbicide than the blanket application treatment (Supporting Information Table S1). It was estimated that the amount of active ingredient applied in the manual application treatment averaged between these two extremes, but data for this are not available.

\section{Effects of herbicide treatment and silage cutting on non-target plants}

There were interaction effects between herbicide type and application method on plant, forb and grass richness and plant diversity. Combining all data, in years one and two following treatment, plant species richness of most treated plots (BD, BF, MD, MF and PD) was significantly lower than that of the control (Table 1, Fig. 1A). Species diversity was also lower in some treatments (BD, BF, MD and MF) compared with the control (Table 1, Fig. 1B). Grass species richness was significantly lower in treatments $\mathrm{MF}$ and MR than the control, whilst forb species richness was lower in treatments $\mathrm{BF}, \mathrm{MD}, \mathrm{MF}$ and $\mathrm{PD}$ compared with the control (Table 1). In each growing season, there was no significant difference in plant richness or diversity in the control plots before and after the first and second silage cuts (Fig. 2). Plant richness in treatments $\mathrm{BD}$ and $\mathrm{BF}$ significantly decreased after the first (BD: $t_{\text {d.f. }}=-3.021_{8} ; \quad P=0.017, \quad B F: t_{\text {d.f. }}=-2.623_{8}$; $P=0.031)$ and second (BD: $t_{\text {d.f. }}=-2.639_{8} ; P=0.030$, BF: $t_{\text {d.f. }}=-2.899_{8} ; P=0.020$ ) silage cuts (Fig. 2). In both the BD and BF treatments, grass species richness, but not forb richness, significantly decreased after the first $\left(\mathrm{BD}: t_{\text {d.f. }}=-2.885_{8} ; \quad P=0.020, \quad \mathrm{BF}: t_{\text {d.f. }}=\right.$ $\left.-2.380_{8} ; P=0.043\right)$ and second (BD: $t_{\text {d.f. }}=-2.370_{8}$; $\left.P=0.045, \mathrm{BF}: t_{\text {d.f. }}=-2.439_{8} ; P=0.041\right)$ silage cuts.

\section{Carry-over effects from the first to the second growing season on non-target plants}

There were no interaction effects on species richness and diversity between treatment and growing season (one and two), except in the case of one treatment (MR). Species richness $\left(t_{\text {d.f. }}=6.054_{425} ; \quad P<0.001\right)$ and diversity $\left(t_{\text {d.f. }}=4.242_{425} ; P<0.001\right)$ of the treatment MR significantly increased in the second growing season compared with the first (Fig. 3). There was no interaction effect on species richness/diversity in the control between silage cutting and growing season.

\section{Pre-versus post-herbicide treatment effects on non-target plants}

Species richness was low at all sites during the first survey period (before the 1st silage cut or before treatments were applied) with an average of 2.0 species $( \pm 0.9 \mathrm{SD})$ per quadrat found at Moorepark, 3.0 species $( \pm 1.8 \mathrm{SD})$ at Oakpark and $4.4( \pm 1.2 \mathrm{SD})$ species at Kilmaley. Despite the low species richness of the sites, when comparing pre- and post- herbicide treatment surveys, significant decreases in species richness in plots that received the $\mathrm{BD}, \mathrm{BF}, \mathrm{MD}$ and MF herbicide treatments were evident (Table 2, Fig. 1A). Grass species richness did not differ between pre- and post-herbicide treatment levels for any herbicide treatment, but forb species richness significantly decreased in plots after $\mathrm{BD}, \mathrm{BF}, \mathrm{MD}$ and MF treatments were applied (Table 2). Total species 
Table 1 Significant differences in non-target plant species richness (total plant, grass and forb) and diversity (total plant) of plots that received eight herbicide treatments compared with control plots that received no herbicide treatment. Data for two experiments and three sites were combined and analysed using linear mixed effects models

\begin{tabular}{|c|c|c|c|c|c|c|c|c|}
\hline \multirow[b]{2}{*}{ Treated plot variation from control } & \multicolumn{2}{|c|}{$\begin{array}{l}\text { Plant species } \\
\text { richness }\end{array}$} & \multicolumn{2}{|c|}{$\begin{array}{l}\text { Grass species } \\
\text { richness }\end{array}$} & \multicolumn{2}{|c|}{$\begin{array}{l}\text { Forb species } \\
\text { richness }\end{array}$} & \multicolumn{2}{|c|}{ Species diversity } \\
\hline & $t_{\text {d.f. }}$ & $P$ & $t_{\text {d.f. }}$ & $P$ & $t_{\text {d.f. }}$ & $P$ & $t_{\text {d.f. }}$ & $P$ \\
\hline Blanket triclopyr-flur & $-3.730_{433}$ & $<0.001$ & - & N.S. & $-4.796_{613}$ & $<0.001$ & $-3.503_{433}$ & 0.001 \\
\hline Blanket aminopyralid-fluroxypyr (BF) & $-5.228_{433}$ & $<0.001$ & - & N.S. & $-8.497_{613}$ & $<0.001$ & $-5.178_{433}$ & $<0.001$ \\
\hline Manual triclopyr-fluroxypyr (MD) & $-3.244_{433}$ & 0.001 & - & N.S. & $-5.952_{613}$ & $<0.001$ & $-2.904_{433}$ & 0.004 \\
\hline Manual aminopyralid-fluroxypyr (MF) & $-7.736_{433}$ & $<0.001$ & $-2.404_{613}$ & 0.017 & $-9.143_{613}$ & $<0.001$ & $-6.274_{433}$ & $<0.001$ \\
\hline Manual glyphosate (MR) & - & N.S. & $-3.264_{613}$ & 0.001 & - & N.S. & - & N.S. \\
\hline Automated triclopyr-fluroxypyr (PD) & $-2.212_{433}$ & 0.028 & - & N.S. & $-2.894_{613}$ & 0.004 & - & N.S. \\
\hline Automated glyphosate (PR) & - & N.S. & - & N.S. & - & N.S. & - & N.S. \\
\hline Automated aminopyralid-fluroxypyr (PF) & - & N.S. & - & N.S. & - & N.S. & - & N.S. \\
\hline
\end{tabular}
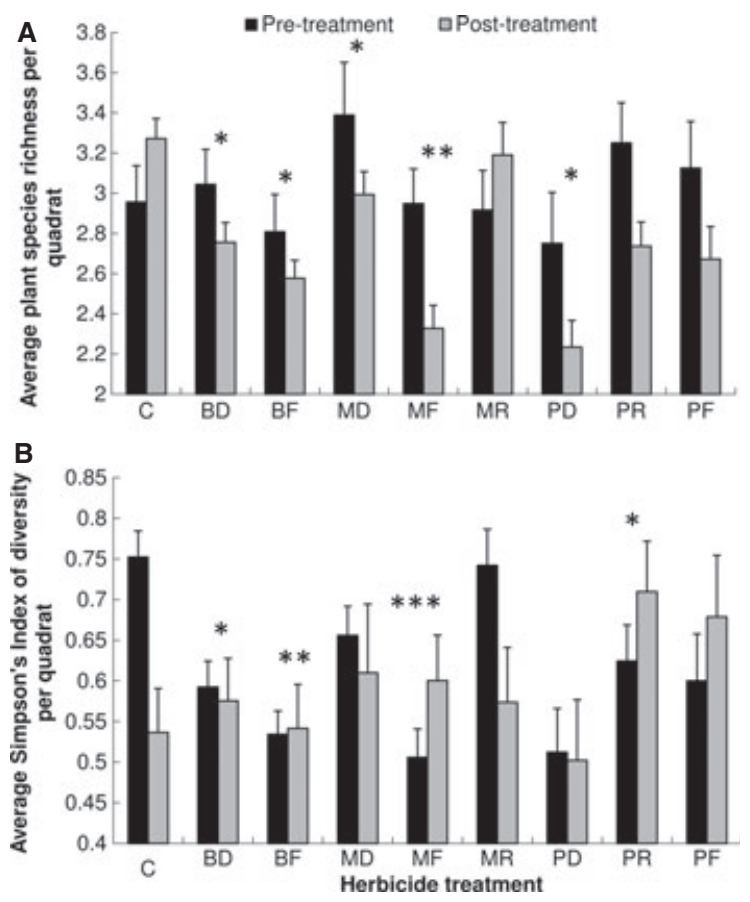

Fig. 1 (A) Average non-target plant species richness and (B) diversity ( \pm standard error) of plots before and after the application of eight different herbicide treatments along with a control (C: no herbicide treatment). All pre-treatment data (for two experiments and three sites) were combined and analysed versus all post-treatment data (for two experiments and three sites) using linear mixed effects models. Herbicide treatments: $\mathrm{BD}=$ blanket triclopyr-fluroxypyr; $\mathrm{BF}=$ blanket aminopyralid-fluroxypyr; $\mathrm{MD}=$ manual triclopyr-fluroxypyr; $\mathrm{MF}=$ manual aminopyralid-fluroxypyr; $\mathrm{MR}=$ manual glyphosate; $\mathrm{PD}=$ automated triclopyr-fluroxypyr; PR = automated glyphosate and PF = automated aminopyralid-fluroxypyr. Significant differences in species richness/diversity before versus after herbicide treatment application compared with the control are illustrated by asterisks $(* P<0.05 ; * * P<0.01 ; * * * P<0.001)$.

diversity also significantly decreased in BD, BF, MF and PR treatments compared with pre-treatment levels (Table 2, Fig. 1B).

\section{Pre- versus post-herbicide treatment effects on} target plants

Before treatments were applied, combined cover of $R$. obtusifolius and R. crispus was greater than $30 \%$ of all Experiment 1 plots and $20 \%$ of all Experiment 2 plots combined. However, Rumex species' distribution was patchy, with $0-80 \%$ coverage in random samples (quadrats) taken in individual plots. The presence of Rumex species decreased significantly in plots receiving the treatments $\mathrm{BF} \quad(z=-2.903 ; \quad P=0.004), \quad \mathrm{MD}$ $(z=-2.416 ; \quad P=0.016) \quad$ and $\quad \mathrm{MF} \quad(z=-4.160$; $P<0.001$ ) only (Fig. 4).

\section{Production}

Production estimates (DM Yield) differed among sites, but there were no significant differences in production among herbicide treatments and no interaction effects between site and treatment on production (Supporting Information Table S2).

\section{Discussion}

\section{Effects of herbicide application method and herbicide type on non-target plants}

Most blanket and manual application treatments reduced non-target plant richness and diversity, compared with the control, whilst the automated application method (except with triclopyr-fluroxypyr) did not. Therefore, depending on the herbicide used and with the aid of more research, novel application technologies such as PPM have the potential to reduce impacts on non-target plant richness and diversity.

The three herbicide products all reduced nontarget plant, forb and grass species richness and diversity, although only triclopyr-fluroxypyr ubiquitously reduced plant/forb richness and diversity 


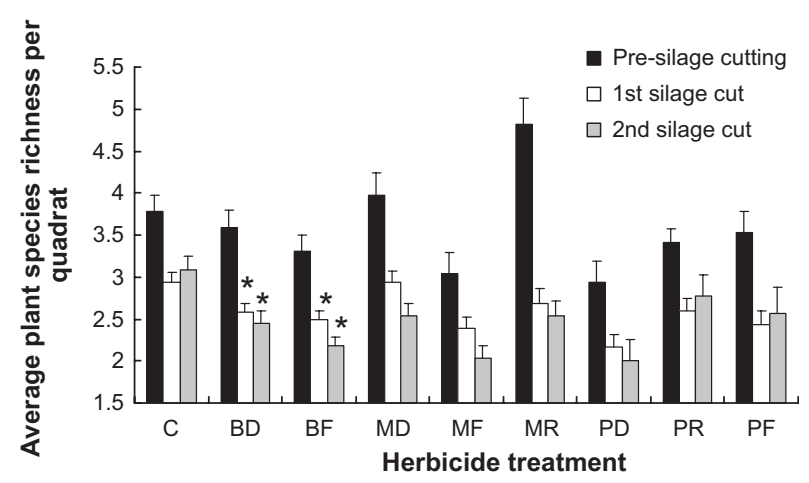

Fig. 2 Average non-target plant species richness ( \pm standard error) before silage cutting and after the first and second silage cuts in control plots (C: no herbicide treatment) and eight herbicide treatments plots. Data for two experiments and three sites were combined and analysed using linear mixed effects models. Herbicide treatments: same as for Fig. 1. Significant differences in species richness pre-silage cutting versus post-silage cutting in the control and each treatment are illustrated by an asterisk $(* P<0.05)$.

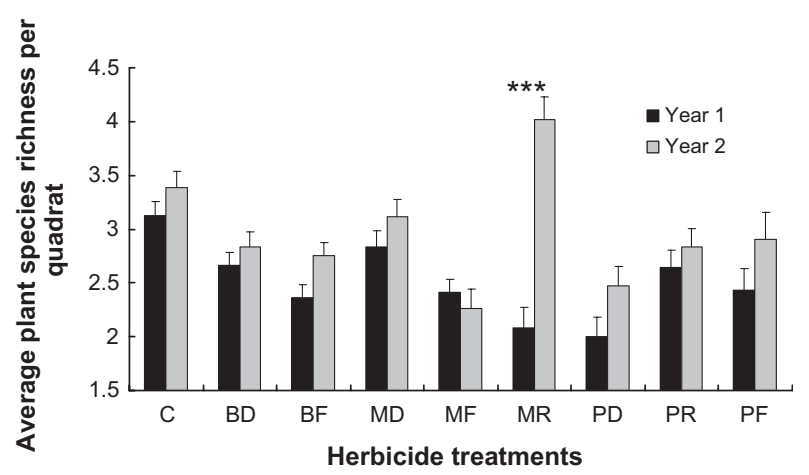

Fig. 3 Average non-target plant species richness ( \pm standard error) of control plots (C: no herbicide treatment) and eight herbicide treatment plots in the first compared with the second growing season. Data for two experiments and three sites were combined and analysed using linear mixed effects models. Herbicide treatments: same as for Fig. 1. A significant difference in species richness between the first and second growing season in the control and each treatment is illustrated by asterisks $(* * * P<0.001)$.

regardless of application method. Triclopyr has not been shown previously to have negative effects on non-target plants and the environment (European Commission, 2006), although negative effects on fungi at concentrations of $1 \mathrm{mg} \mathrm{L}^{-1}$ have been reported (Estok et al., 1989). Fluroxypyr is used to control a wide range of broad-leaved weeds $(\mathrm{Yu}$ et al., 2007) and is known to accumulate in soils (e.g. $8 \mathrm{mg} \mathrm{kg}^{-1}$ : Tao \& Yang, 2011) and to disrupt processes in crop plant tissues at concentrations of $0.1 \mathrm{mg} \mathrm{l}^{-1}$ (Wu et al., 2010). Application of aminopyralid-fluroxypyr (using traditional application methods only) reduced total plant, forb and grass richness and diversity at application levels of $694 \mathrm{~g}$ a.

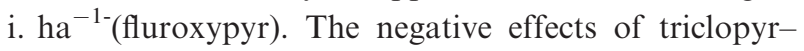
fluroxypyr and aminopyralid-fluroxypyr on nontarget plants indicate that caution is required before application of these herbicide formulations.

Glyphosate did not decrease non-target plant and forb richness and diversity (using the manual or automated method), but grass species richness decreased (compared with the control) when glyphosate was applied manually. There is a large genetic variation in tolerance among some grass species to glyphosate toxicity (Su et al., 2009), but its effects on grass species richness in our study indicate that caution is required when applying this herbicide in grassland systems. Although not detected in our study, glyphosate can alter non-target plant fecundity through spray drift (Marrs \& Frost, 1997) and uptake through the rhizosphere (Tesfamariam et al., 2009). We found that more precise application of potent herbicides, such as glyphosate, can minimise effects on non-target plants. This is important as glyphosate is the most widely used herbicide in the world (Woodburn, 2000). Glyphosate can negatively affect plant nutrient availability, susceptible crops, microorganisms and plant pathogens, and also select for herbicide-resistant weeds in glyphosateresistant cropping systems (e.g. Roundup Ready, Monsanto). These issues have raised concerns regarding the sustainability of agricultural systems in which glyphosate is the primary weed management strategy (Yamada et al., 2009). More targeted and controlled application methods, such as the PPM technology we use in our study, can reduce the impacts of herbicides such as glyphosate and aminopyralid-fluroxypyr on non-target plants and so merit further research and development.

\section{Silage-cutting interaction with herbicide treatment and non-target plants}

In nutrient-rich, heavily managed habitats such as intensive grasslands, only the most competitive of weed species survive, and so, silage-cutting alone is not likely to have major impacts on these remaining species. However, effects of some herbicide treatments on nontarget plants were exacerbated by silage cutting. Although triclopyr-fluroxypyr and aminopyralid-fluroxypyr are not designed to kill grasses, they may cause additional stress to some grass species and reduce their resilience to intensive defoliation associated with successive silage cutting. Therefore, herbicides that are generally used in arable systems (e.g. fluroxypyr: European Commission, 1999) may not behave as expected in grassland systems where target and non-target 
Table 2 Significant differences in non-target plant species richness (total plant, grass and forb) and diversity (total plant) of plots before and after they received eight herbicide treatments and control plots that received no herbicide treatment. Data for two experiments and three sites were combined and analysed using linear mixed effects models

\begin{tabular}{|c|c|c|c|c|c|c|c|c|}
\hline \multirow[b]{2}{*}{ Pre-versus post-herbicide treatment } & \multicolumn{2}{|c|}{$\begin{array}{l}\text { Plant species } \\
\text { richness }\end{array}$} & \multicolumn{2}{|c|}{$\begin{array}{l}\text { Grass } \\
\text { species } \\
\text { richness }\end{array}$} & \multicolumn{2}{|c|}{$\begin{array}{l}\text { Forb species } \\
\text { richness }\end{array}$} & \multicolumn{2}{|c|}{ Species diversity } \\
\hline & $t_{\text {d.f. }}$ & $P$ & $t_{\text {d.f. }}$ & $P$ & $t_{\text {d.f. }}$ & $P$ & $t_{\text {d.f. }}$ & $P$ \\
\hline Blanket triclopyr-fluroxypyr (BD) & $-2.304_{605}$ & 0.022 & - & N.S. & $-2.207_{605}$ & 0.028 & $-2.439_{605}$ & 0.015 \\
\hline Blanket aminopyralid-fluroxypyr (BF) & $-2.352_{605}$ & 0.019 & - & N.S. & $-3.748_{605}$ & $<0.001$ & $-3.072_{605}$ & 0.002 \\
\hline Manual triclopyr-fluroxypyr (MD) & $-2.109_{605}$ & 0.035 & - & N.S. & $-3.126_{605}$ & 0.002 & - & N.S. \\
\hline Manual aminopyralid-fluroxypyr (MF) & $-2.676_{605}$ & 0.008 & - & N.S. & $-3.886_{605}$ & $<0.001$ & $-3.511_{605}$ & 0.001 \\
\hline Manual glyphosate (MR) & - & N.S. & - & N.S. & - & N.S. & - & N.S. \\
\hline Automated triclopyr-fluroxypyr (PD) & - & N.S. & - & N.S. & - & N.S. & - & N.S. \\
\hline Automated glyphosate (PR) & - & N.S. & - & N.S. & - & N.S. & $-2.131_{605}$ & 0.034 \\
\hline Automated aminopyralid-fluroxypyr (PF) & - & N.S. & - & N.S. & - & N.S. & - & N.S. \\
\hline
\end{tabular}

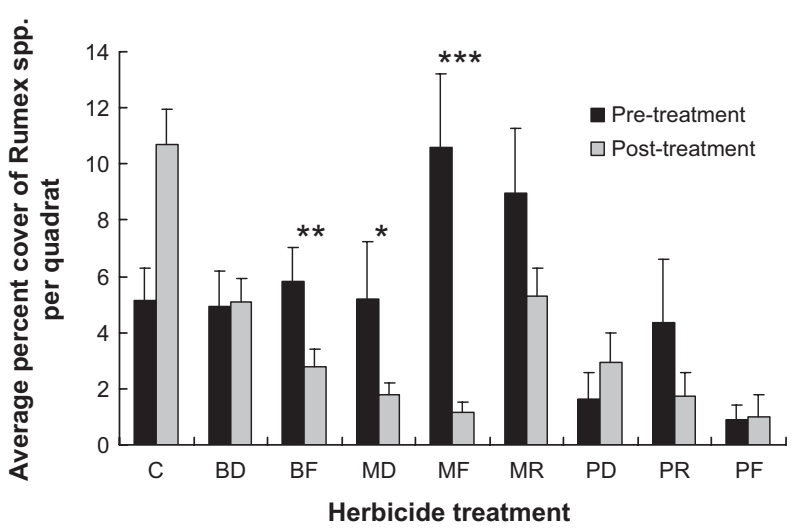

Fig. 4 Average percentage cover ( \pm standard error) of the target weed species, Rumex species, in control plots (C: no herbicide treatment) and in eight herbicide treatment plots before and after treatments was applied. Data for two experiments and three sites were combined and analysed using generalised linear mixed effects models (using the binomial distribution). Herbicide treatments: same as for Fig. 1. Significant post-treatment decreases in the presence of Rumex species in all herbicide treatment plots and the control are illustrated by asterisks $(* P<0.05 ; * * P<0.01$; $* * * P<0.001)$.

plants are subject to very different disturbance/defoliation regimes.

\section{Carry-over effects on non-target plants}

Carry-over effects of aminopyralid-fluroxypyr and triclopyr-fluroxypyr on plant richness and diversity were not found in our study. These herbicides are not thought to persist in soils beyond one season (European Commission, 1999). To date, carry-over effects of glyphosate in grassland systems have not been demonstrated either. However, in our study, plots treated with manual applications of glyphosate were found to increase significantly in non-target plant species richness and diversity from the first to the second growing season, but not plots treated by automated spot-spraying. It is probable that the manual application method used more active ingredient per unit area than the automated method. This, coupled with the fact that glyphosate application opened up significantly more open spaces in the sward than other herbicides (Creighton et al., 2011), probably allowed for colonisation of new plant species and thus increased non-target plant species richness.

\section{Pre- versus post-herbicide treatment effects on target and non-target plants}

Herbicide treatment effects on target plant presence/ absence and on non-target plant richness and diversity were similar. None of the herbicide treatments in our study significantly reduced the presence of target plants whilst leaving non-target plant richness unaffected. One treatment, blanket triclopyr-fluroxypyr, did not reduce target plants, but succeeded in reducing non-target plant richness.

Targeted area spraying (spraying of weed-infested areas of a field) has been researched for use in arable crops (Blair et al., 2002), but targeted spot-spraying of individual weeds is less well developed in arable crops and has not been evaluated in grassland. The automated application technology used in our study had limited negative impacts on non-target plants. However, it was not found to be effective at controlling target plants either (but see: Creighton et al., 2011). This may be partly because the automated application technology used less active ingredient per unit treated area than the equivalent blanket application in Experiment 2. Our research indicates that, although this technology has potential, further research and development is required (in terms of plant ID and herbicide volume control) before it could be considered both effective at weed control and environmentally friendly, and hence 
a valid replacement of traditional herbicide application methods.

\section{Production}

Despite significant differences among post-herbicide treatments in relation to non-target plant richness and diversity and target plant presence, no significant differences in production levels were observed. It is widely accepted that ryegrass-dominated pastures are more productive, in terms of DM production, than their weed-infested counterparts (Haggar, 1971), and weed control is often initiated if weeds constitute at least $20-30 \%$ of the sward (levels thought to impact on sward productivity and quality) (Oswald \& Haggar, 1983). However, our results indicate that $20-30 \%$ weed infestation does not significantly alter production in permanent grasslands. Increased botanical diversity in the sward may even increase production (Sanderson et al., 2004). Indeed, more diverse swards may be nutritionally superior (Rackham, 1986). If plants toxic to livestock are absent from grasslands, we advocate caution before applying herbicides (particularly using traditional methods), as such applications are expensive and their effects on non-target organisms and the environment can be much more significant than their benefits to production.

\section{Acknowledgements}

We thank our collaborative partners in Teagasc Moorepark and Oakpark and University College Dublin for project management and experimental design and implementation, Gramenor for PPM System design and operation, Philip Creighton for production data contribution and comments on the manuscript and Teagasc staff for herbicide trial assistance. There is no conflict of interest associated with this research. This project, part of a collaborative project led by Michael O'Donovan of Teagasc Moorepark, was funded by the Irish Department of Agriculture, Fisheries and Food Research Stimulus Fund (RSF) under the National Development Plan (2007-2013).

\section{References}

Andreasen C \& Streibig JC (2010) Evaluation of changes in weed flora in arable fields of Nordic countries based on Danish long-term surveys. Weed Research 51, 214-226.

BastiaAns L, Paolini R \& Baumann DT (2008) Focus on ecological weed management: what is hindering adoption? Weed Research 48, 481-491.

BATES D \& SARKAR D (2006) lme4: Linear mixed-effects models using S4 classes. R package version 0.9975-10.
Available at: http://cran.r-project.org/web/packages/lme4/ index.html (last accessed 14 September 2012).

Blair AM, Jones PA, Ingle RH, Tillet ND \& Hague T (2002) The integration of herbicides with mechanical weeding for weed control in winter wheat. Journal of Agricultural Science 139, 385-395.

Brown L, Soltani N, Shropshire C, Spieser H \& Sikkema PH (2007) Efficacy of four corn (Zea mays L.) herbicides when applied with flat fan and air induction nozzles. Weed Biology and Management 7, 55-61.

Central Statistics Office (2010) Areas under selected crops, Ireland. Available at: http://www.cso.ie/en/media/csoie/ releasespublications/documents/agriculture/ farmingsincethefamine/Table\%2010.pdf (last accessed 14 September 2012) [Online].

Creighton P, Kennedy E, Boland TM \& O'donovan M (2011) Published. Control of Rumex obtusifolius L. species as dictated by herbicide application strategy. In:

Proceedings 2011 Agricultural Research Forum Conference (14th-15th March Tullamore, Offaly, Ireland). 154 Teagasc, Ireland.

Estok D, Freedman B \& Boyle D (1989) Effects of the herbicides 2,4-D, glyphosate, hexazinone, and triclopyr on the growth of three species of ectomycorrhizal fungi. Bulletin of Environmental Contamination and Toxicology 42, 835-839.

European Commission (1999) Review report for the active substance fluroxypyr. Unit E.1: Legislation relating to crop products and animal nutrition. Directorate-General Health \& Consumer Protection

European Commission (2006) Review report for the active substance triclopyr SANCO/10010/2006 - rev. 3. Directorate E - Safety of the food chain. European Commission Health and Consumer Protection DirectorateGeneral.

Gebhardt S, Schellberg J, Lock R \& Kühbauch W (2006) Identification of broad-leaved dock (Rumex obtusifolius L.) on grassland by means of digital image processing. Precision Agriculture 7, 165-178.

Haggar RJ (1971) The significance and control of Poa trivialis in ryegrass pastures. Grass and Forage Science 26, 117-122.

Marrs RH \& Frost AJ (1997) A microcosm approach to the detection of the effects of herbicide spray drift in plant communities. Journal of Environmental Management 50, 369-388.

Marshall EJP, Brown VK, Boatman ND, Lutman PJW, SQuire GR \& WARD LK (2003) The role of weeds in supporting biological diversity within crop fields. Weed Research 43, 77-89.

Mcloughlin D (2011) Automated Spot-spraying Machine [Online]. Cork. Available: www.gramenor.com (last accessed 14th September 2012).

Oswald AK \& Haggar RJ (1983) The effects of Rumex obtusifolius on the seasonal yield of two mainly perennial ryegrass swards. Grass \& Forage Science 38, 187-191.

Pinheiro J, Bates D, Debroy S \& Sarkar D \& The R Core Team (2009) nlme: Linear and Nonlinear Mixed Effects Models. R package version 3.1-96, Available at: http:// CRAN.R-project.org $/$ package $=$ nlme (last accessed 14 September 2012). 
Plantureux S, Peeters A \& Mccracken D (2005) Biodiversity in intensive grasslands: effect of management, improvement and challenges. Agronomy Research 3, 152-164.

R Development Core Team (2007) R: A Language and Environment for Statistical Computing. R Foundation for Statistical Computing Vienna, Austria. ISBN 3-900051-070, Available at: http://www.R-project.org (last accessed 30 August 2012).

Racкham O (1986) The History of the Countryside. Dent, London, UK.

Sanderson MA, Skinner RH, Barker DJ, Edwards GR, Tracy BF \& Wedin DA (2004) Plant species diversity and management of temperate forage and grazing land ecosystems. Crop Science 44, 1132-1144.

SAS Institute (2002) Users Guide: Statistics, Cary, NC.

SHAw I (1999) Pesticides in food. In: Pesticide Chemistry and Bioscience. The Food-Environment Challenge (eds GT Brooks \& TR Roberts), 421-428. Royal Society of Chemistry, Cambridge, UK.

SimPSON EH (1949) Measurement of diversity. Nature 163, 688. Stace CA (2010) New Flora of the British Isles. Cambridge University Press, Cambridge, UK.

Steen RJCA, Leonards PEG, Brinkman UAT et al. (1999) Ecological risk assessment of agrochemicals in European estuaries. Environmental Toxicology \& Chemistry 18, 1574-1581.

Su YS, Ozturk L, Cakmak I \& Budak H (2009) Turfgrass species response exposed to increasing rates of glyphosate application. European Journal of Agronomy 31, 120-125.

Sutcliffe OL \& KAY QON (2000) Changes in the arable flora of central southern England since the 1960s.

Biological Conservation 93, 1-8.

TAO L \& YANG H (2011) Fluroxypyr biodegradation in soils by multiple factors. Environmental Monitoring and Assessment 175, 227-238.

Tesfamariam T, Bott S, Cakmak I, Romheld V \& Neumann G (2009) Glyphosate in the rhizosphere-Role of waiting times and different glyphosate binding forms in soils for phytotoxicity to non-target plants. European Journal of Agronomy 31, 126-132.

Tillett ND, Hague T \& Marchant JA (1998) A robotic system for plant-scale husbandry. Journal of Agricultural Engineering Research 69, 169-178.
Vickery JA, Tallowin JR, Feber RE et al. (2001) The management of lowland neutral grasslands in Britain: effects of agricultural practices on birds and their food resources. Journal of Applied Ecology 38, 647-664.

Woodburn AT (2000) Glyphosate: production, pricing and use worldwide. Pest Management Science 56, 309-312.

Wu G, Cui J, Tao L \& Yang H (2010) Fluroxypyr triggers oxidative damage by producing superoxide and hydrogen peroxide in rice (Oryza sativa). Ecotoxicology 19, 124-132.

Yamada T, Kremer RJ, Castro P \& Wood BW (2009) Glyphosate interactions with physiology, nutrition, and diseases of plants: threat to agricultural sustainability? Preface. European Journal of Agronomy 31, 111-113.

Yu LQ, Yoshinaru Z, Zhou YJ, Zhang JP \& Lu YL (2007) Response of exotic invasive weed Alternanthera philoxeroides to environmental factors and its competition with rice. Rice Science 14, 49-55.

Zuur AF, Ieno EN, Walker NJ, Saveliev AA \& Smith GM (2009) Mixed Effects Models and Extensions in Ecology with R. Springer, New York.

\section{Supporting Information}

Additional Supporting Information may be found in the online version of this article:

Figure S1 Total percentage cover of all species at three sites prior to treatment application and silage cutting.

Figure S2 Replicated randomised block design at three study sites.

Table S1 The amount of active ingredient of each herbicide applied using the automated and blanket application methods.

Table S2 Mean DM yields (kg DM ha ${ }^{-1}$ ) of each herbicide treatment at each silage cut and site with significant differences in DM yields between herbicide treatments and sites and their interaction. 